\title{
The Role of Ceruloplasmin in Iron Metabolism
}

\author{
H. P. Roeser, G. R. Lee, S. Nacht, and G. E. Cartwright \\ From the Department of Internal Medicine, University of Utah College of \\ Medicine, Salt Lake City, Utah 84112
}

A B S T R A C T The importance of ceruloplasmin in iron metabolism was studied in swine made hypoceruloplasminemic by copper deprivation. When the plasma ceruloplasmin level fell below $1 \%$ of normal, cell-to-plasma iron flow became sufficiently impaired to cause hypoferremia, even though total body iron stores were normal. When ceruloplasmin was administered to such animals, plasma iron increased immediately and continued to rise at a rate proportional to the logarithm of the ceruloplasmin dose. The administration of inorganic copper induced increases in plasma iron only after ceruloplasmin appeared in the circulation. Thus, ceruloplasmin appeared to be essential to the normal movement of iron from cells to plasma.

Studies designed to define the mechanism of action of ceruloplasmin were based on the in vitro observation that ceruloplasmin behaves as an enzyme (ferroxidase) that catalyzes oxidation of ferrous iron. Retention of injected ferrous iron in the plasma of ceruloplasmin-deficient swine was significantly less than that of ferric iron, reflecting impaired transferrin iron binding. Rat ceruloplasmin, which has little ferroxidase activity, was much less effective than porcine or human ceruloplasmin in inducing increases in plasma iron. These observations suggest that ceruloplasmin acts by virtue of its ferroxidase activity.

Eight patients with Wilson's disease were evaluated in order to investigate iron metabolism in a disorder characterized by reduced ceruloplasmin levels. Evidence of iron deficiency was found in six of these, and in five of the six, plasma ceruloplasmin was less than $5 \%$ of normal. In comparison, the two patients without evidence of iron deficiency had ceruloplasmin levels of 11 and $18 \%$ of normal. It is suggested that iron deficiency tends to occur in those patients with Wilson's disease who have the severest degrees of hypoceruloplasminemia, possibly because of defective transfer of iron from intestinal mucosal cells to plasma.

Portions of this work were reported previously in abstract form (1970. J. Clin. Invest. 49: 55 a.)

Dr. Lee is a Markle Scholar in Academic Medicine.

Received for publication 21 July 1970.

\section{INTRODUCTION}

The rate of oxidation of ferrous iron by molecular oxygen is greatly accelerated in vitro by the plasma copper protein, ceruloplasmin $(1,2)$. On the basis of this enzymatic activity, ceruloplasmin has been classified as a ferro- $\mathrm{O}_{2}$-oxidoreductase and designated ferroxidase.

It has been proposed that the enzymatic oxidation of ferrous iron is an essential step in the formation of transferrin (1). This hypothesis holds that iron is presented to the cell surface in the reduced form, that it is then oxidized to ferric iron, and that the ferric iron so formed is bound by apotransferrin more rapidly than ferrous iron would be.

The physiologic need for the enzymatic oxidation of iron may be questioned because spontaneous oxidation of iron occurs readily in the presence of molecular oxygen and is accelerated by nonprotein substances present in normal plasma, particularly citrate (3). Osaki, Johnson, and Frieden (1) approached the problem of the relative importance of the spontaneous and the enzymatic reactions by studying their kinetics in plasma. The nonenzymatic rate of iron oxidation was found to be dependent on a number of factors, including $\mathrm{pH}$ and the concentrations of oxygen and ferrous ion. When certain assumptions were made about the physiologic status of these factors, it was calculated that the amount of ferrous iron that could be oxidized in plasma each day by means of the nonenzymatic reaction was less than that which normally flowed into plasma from the reticuloendothelial system. These calculations supported the need for the ferroxidase activity of ceruloplasmin in iron metabolism.

In our studies of copper-deficient swine, abnormalities in iron metabolism were found which may be cited as in vivo evidence for the above hypothesis. In these animals, the ability of mucosal cells, reticuloendothelial cells, and hepatic parenchymal cells to release iron to the plasma is impaired (4). Furthermore, the administration of ceruloplasmin induces a rapid, sustained increase in plasma iron as a result of an increased flow of iron into plasma (5). 
The purpose of the present study is to provide additional in vivo evidence for the function of ceruloplasmin described above.

If ceruloplasmin functions physiologically as a ferroxidase in promoting the rate of transferrin formation, and if the abnormalities in iron metabolism observed in copper-deficient swine are to be ascribed to a deficiency of ceruloplasmin ferroxidase activity, it then follows that in such animals: $(a)$ there must be a deficiency of ceruloplasmin; (b) the deficiency of ceruloplasmin should precede the restriction in the flow of iron into plasma as manifested by the development of hypoferremia; $(c)$ an increase in ceruloplasmin in the circulation should precede the increase in plasma iron which follows the administration of copper; $(d)$ the rate of transferrin formation in vivo from intravenously injected ferrous iron should be slower than that from intravenously administered ferric iron; $(e)$ a rapid increase in plasma iron should occur following intravenous administration of ceruloplasmin; $(f)$ there should be little response to a ceruloplasmin with little ferroxidase activity; $(g)$ there should be little response to an intravenous injection of an active ferroxidase (asialoceruloplasmin) which is rapidly removed from the circulation by the liver, and finally, $(h)$ abnormalities of iron metabolism must be searched for in patients with Wilson's disease and related to the degree of ceruloplasmin deficiency in such patients.

\section{MATERIALS AND METHODS}

Pigs were obtained at 5 to 6 days of age and fed a copperand iron-deficient diet consisting entirely of canned condensed milk. Copper as copper sulfate was added to the control diet. Both control and deficient pigs were given $2.0 \mathrm{~g}$ iron intramuscularly in the form of iron dextrins (Pigdex) during the first 3 to $4 \mathrm{wk}$ of life. No other sources of iron were provided. Additional details of diet preparation and animal care have been published $(4,6)$.

Porcine, rat, and human ceruloplasmins were prepared by a method reported elsewhere (7). Asialoceruloplasmin was prepared from porcine ceruloplasmin by means of a modification of the method of Morell, van den Hamer, Scheinberg, and Ashwell (8). The enzymatic digestion of ceruloplasmin by neuraminidase was carried out for $24 \mathrm{hr}$ in dialysis casings with continuous dialysis to remove sialic acid. Less than $1 \%$ of the original sialic acid content remained after this procedure. Removal of neuraminidase from the incubation medium was accomplished by repeated ultrafiltration in Centriflo membrane cones, type XM-50 (Amicon Instrument Corp., New York).

Iron solutions for intravenous injection were prepared on the day of the experiment. Ferric iron solutions were stabilized by the addition of sufficient trisodium citrate to produce a final citrate: iron molar ratio of 20:1 (9). Ascorbic acid was added to the ferrous iron solutions in a concentration of $10 \mathrm{mg} / \mathrm{ml}$. Final iron concentration in both solutions was $0.1 \mathrm{mg} / \mathrm{ml}$.

The following three methods were used to estimate plasma ceruloplasmin concentration. (a) Paraphenylenediamine (pPD) oxidase activity was assayed by the method of Ravin (10), modified by the use of up to $1 \mathrm{ml}$ of plasma when ceruloplasmin levels were low. This technique was considered to be the most accurate measure of ceruloplasmin at low concentrations.

(b) Ferroxidase activity was assayed before and after the addition of azide as reported elsewhere (3). "Total" ferroxidase (measured in the absence of azide) includes the activity due to ceruloplasmin as well as that due to citrate. "Nonceruloplasmin" ferroxidase (assayed in the presence of azide) measures the activity of citrate. "Ceruloplasmin ferroxidase" is calculated from the difference of these two measurements and therefore tends to be a less accurate measure of ceruloplasmin at low levels than $\mathrm{pPD}$ oxidase activity.

(c) Plasma copper was determined by atomic absorption spectrophotometry after deproteinization by the method of Trinder (11). Since this technique measures albumin-bound as well as ceruloplasmin copper, it is not an accurate measure of ceruloplasmin at low levels.

Methods for routine hematologic studies, bone marrow iron stains, and total iron-binding capacity have been published (12). Iron in plasma and various experimental preparations was measured by a technique similar to that for estimating copper.

\section{RESULTS}

Plasma ceruloplasmin concentration in copper deficiency. Markedly reduced plasma ceruloplasmin levels were found consistently in copper-deficient pigs, regardless of the ceruloplasmin assay used (Table I). After 73 days of copper deprivation, the ceruloplasmin concentration was less than $2 \%$ of normal as estimated by the ceruloplasmin ferroxidase technique and less than $0.5 \%$ of normal by the more accurate $\mathrm{pPD}$ oxidase assay. The plasma copper and total plasma ferroxidase were reduced to lesser degrees, but these measures are not specific for ceruloplasmin (see Methods). Nonceruloplasmin ferroxidase, which is a reflection of citrate concentration, was similar in control and copper-deficient pigs.

TABLE I

Measures of Plasma Ceruloplasmin in Control and Copper Deficient Pigs*

\begin{tabular}{|c|c|c|c|}
\hline & Control & $\begin{array}{l}\text { Copper } \\
\text { deficientł }\end{array}$ & $\begin{array}{l}\text { Deficient } \\
\text { as } \% \text { of } \\
\text { control }\end{array}$ \\
\hline Number & 15 & 9 & \\
\hline $\begin{array}{l}\text { Plasma copper, } \\
\mu g / 100 \mathrm{ml} \\
\text { pPD oxidase, }\end{array}$ & $199 \pm 24$ & $19 \pm 6$ & $10 \%$ \\
\hline 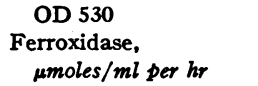 & $0.59 \pm 0.13$ & $0.0018 \pm 0.0013$ & $0.3 \%$ \\
\hline Total & $156 \pm 24$ & $21 \pm 4$ & $13 \%$ \\
\hline Nonceruloplasmin & $18 \pm 3$ & $20 \pm 3$ & $111 \%$ \\
\hline Ceruloplasmin & $139 \pm 24$ & $1.4 \pm 2.3$ & $1 \%$ \\
\hline
\end{tabular}

* Values are mean \pm 1 SD.

$¥$ After 73 days on copper-deficient diet. 
Relation of ceruloplasmin deficiency to the development of hypoferremia. In a previous investigation we observed that copper-deficient pigs developed transient hypoferremia, even though their iron stores were normal (4). The time course of the development of hypoferremia and its relation to plasma ceruloplasmin levels was studied in 10 such episodes of hypoferremia. A typical episode and its relation to plasma ceruloplasmin is illustrated in Fig. 1. The onset of hypoferremia occurred after an average of $9.5 \mathrm{wk}$ (range 7-12) of copper deprivation. In each pig, a severe degree of hypoceruloplasminemia was observed before the plasma iron decreased. The average value for plasma $\mathrm{pPD}$ oxidase activity at the onset of hypoferremia was 0.0034 (range $0.0006-0.007)$. This is a value that is about $0.5 \%$ of normal (Table I).

Relation of plasma iron to plasma ceruloplasmin levels after copper administration. We reported previously that the intravenous administration of inorganic copper (100 $\mu \mathrm{g} / \mathrm{kg}$ of body weight) to copper-deficient pigs was followed by an increase in plasma iron (4). To ascertain whether this phenomenon was preceded by the appearance of ceruloplasmin in the plasma, the changes in both pPD oxidase activity and plasma iron were monitored after copper administration (Fig. 2).

The plasma $\mathrm{pPD}$ oxidase activity increased within 15 min after the injection of copper and continued to increase linearly for $3 \mathrm{hr}$. Little change in the plasma iron concentration was observed during the first $30 \mathrm{~min}$. Only after the oxidase activity reached $1 \%$ of normal did the plasma iron increase begin, and then it increased abruptly and rose more than $100 \mu \mathrm{g} / 100 \mathrm{ml}$ in the ensuing $2.5 \mathrm{hr}$.

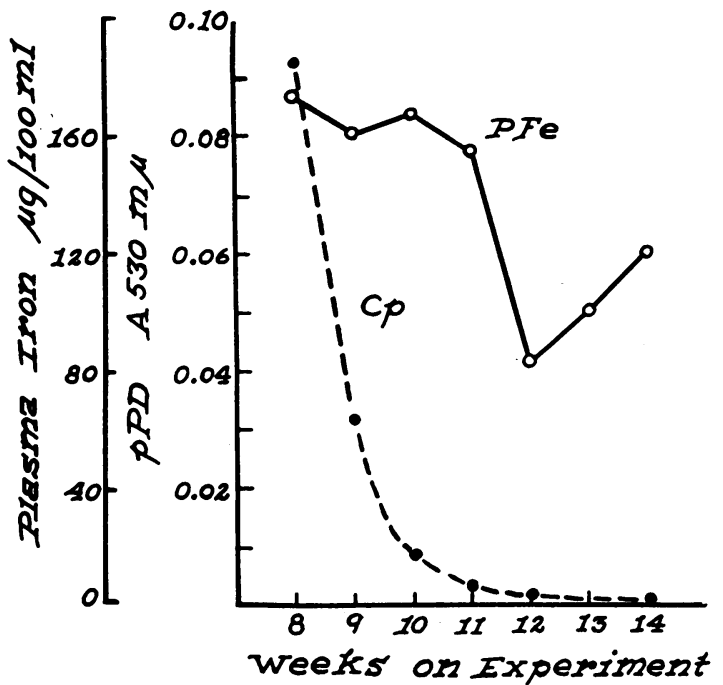

FIGURE 1 The relation of plasma ceruloplasmin $(\mathrm{Cp})$ to the onset of hypoferremia in a copper-deficient pig. $\mathrm{PFe}$, plasma iron; pPD, $p$-phenylenediamine oxidase activity.
Binding of iron by transferrin after intravenous injection of ferrous and ferric iron. If the spontaneous oxidation of iron were rapid enough to insure binding to transferrin, there would be no physiologic need for a plasma enzyme with ferroxidase activity. To test the relative efficiency of the spontaneous and enzymatic reactions in an in vivo system, the effect of an injection of ferrous iron was compared with that of ferric iron in control and copper-deficient pigs. In each case, the amount of iron injected was $200 \mu \mathrm{g} / 100 \mathrm{ml}$ estimated plasma volume (13) and the increase in plasma iron 10 min after the injection was determined.

When ferric iron was injected, there was no difference between the plasma iron values in control and copperdeficient animals. In contrast, when ferrous iron was injected, the subsequent plasma iron values were considerably lower in deficient animals than in controls (Table II).

The consequences of defective plasma iron binding were further demonstrated by injecting radioactive ferrous iron in the same doses described above and observing the amount of the radioactivity retained in plasma. In a control animal, $85 \%$ of the radioactivity was found in the plasma $10 \mathrm{~min}$ after the injection, whereas a mean of only $31 \%$ was found in the plasma of four copper-deficient animals.

Influence of ceruloplasmin administration on plasma iron. We reported previously that the injection of ceruloplasmin induced an increase in plasma iron in copper-deficient pigs (4). In the present investigation, the relation of this phenomenon to the amount of ceruloplasmin injected was studied. Ceruloplasmin was given in doses calculated to increase the plasma ceruloplasmin level by $0.1,0.5,1.0$, and $10 \%$ of normal, respectively. Details on the doses used and the levels of pPD oxidase achieved are given in Table III.

Both the rate of increase in plasma iron concentration and the maximum value achieved appeared to be related to the amount of ceruloplasmin administered (Fig. 3). A linear relation was observed between the "initial" rate of plasma iron increase, as estimated by the value at $30 \mathrm{~min}$, and the logarithm of the plasma ceruloplasmin concentration after the injection (Fig. 4).

Influence of rat and human ceruloplasmin on plasma iron. Rat ceruloplasmin is capable of oxidizing $\mathrm{pPD}$ but possesses little ferroxidase activity as compared with porcine ceruloplasmin (Table IV). Rat and porcine ceruloplasmins were injected intravenously into copperdeficient pigs to evaluate the importance of ferroxidase activity in the induction of plasma iron changes. Equivalent amounts of the two proteins, as judged by pPD oxidase activity, were injected. Rat ceruloplasmin was found to have considerably less effect on the plasma iron than porcine ceruloplasmin (Fig. $5 A$ ). 


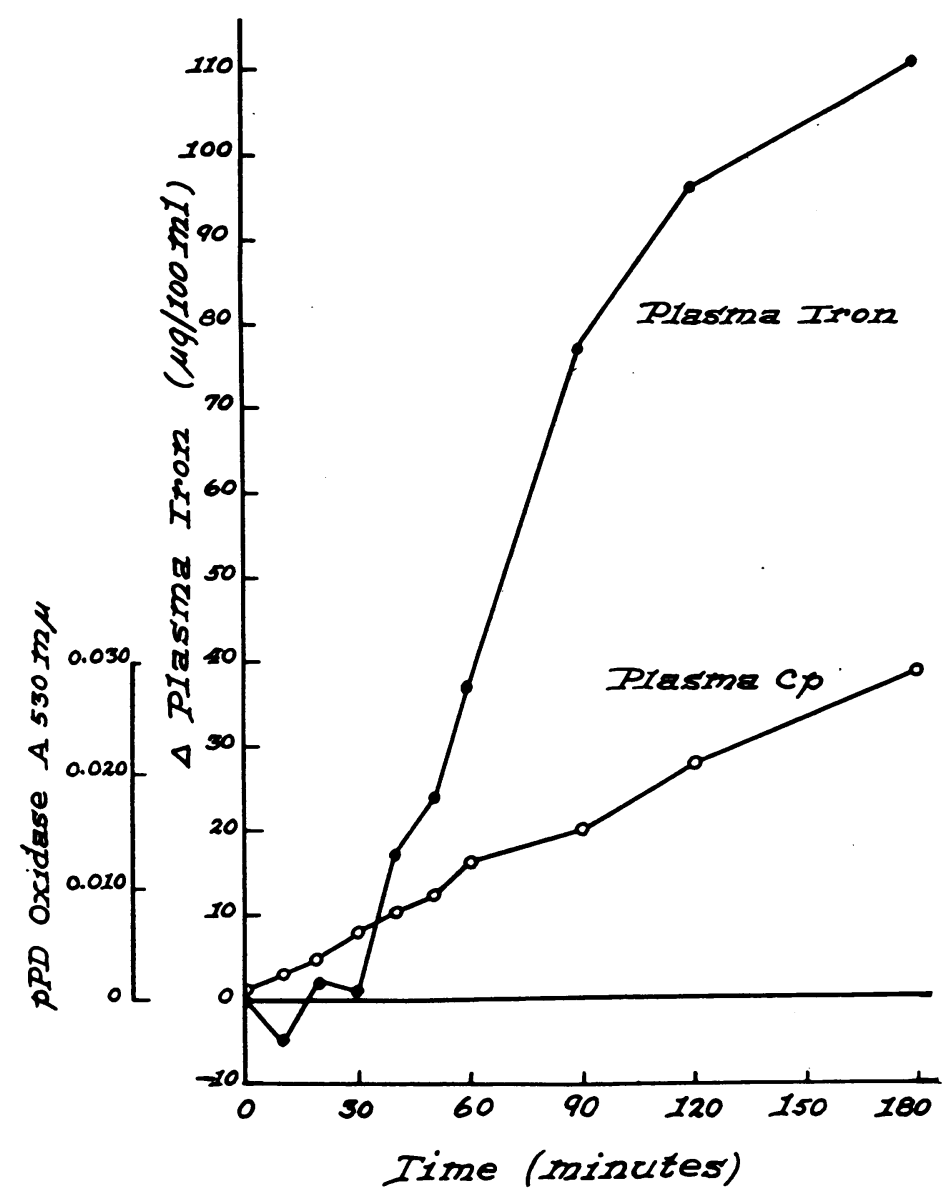

Figure 2 Changes in plasma iron and plasma ceruloplasmin ( $\mathrm{Cp}$ ) after the administration of copper sulfate to copper-deficient pigs. The mean of two experiments in which 100 and $150 \mu \mathrm{g}$ of copper per $\mathrm{kg}$ body weight respectively were administered is illustrated. An increase in $\mathrm{Cp}$ precedes the change in plasma $\mathrm{Fe}$.

It might be argued that ceruloplasmin is species-specific in regard to its ability to increase the plasma iron concentration. However, the administration of a "10\%" dose (Table III) of human ceruloplasmin to copper-de-

TABLE II

Effect of an Intravenous Iron Injection on Plasma Iron Concentration*

\begin{tabular}{llcc}
\hline & \multicolumn{2}{c}{ Increase in plasma iron } \\
\cline { 2 - 3 } Injection & Control & $\begin{array}{c}\text { Copper } \\
\text { deficient }\end{array}$ & \\
\hline & $\mu g / 100 m l$ & $\mu g / 100 m l$ & $P$ \\
Ferric & $145 \pm 35$ & $140 \pm 30$ & $>0.05$ \\
Ferrous & $182 \pm 52$ & $91 \pm 23$ & $<0.001$ \\
& $P>0.05$ & $P<0.001$ &
\end{tabular}

* Values are mean \pm SD of 9 to 13 experiments. $P$, probability of significant difference ( $t$ test). ficient pigs induced an increase in plasma iron of $169 \mu \mathrm{g} /$ $100 \mathrm{ml}$ in $180 \mathrm{~min}$.

Influence of porcine asialoceruloplasmin on plasma iron. The removal of sialic acid from ceruloplasmin

TABLE III

Amount of Ceruloplasmin Copper Administered

\begin{tabular}{|c|c|c|c|c|c|c|}
\hline $\begin{array}{c}\text { Intended } \\
\% \text { of } \\
\text { normal }\end{array}$ & $\mathbf{N}$ & $\begin{array}{c}\text { Body } \\
\text { weight }\end{array}$ & Total & & $\begin{array}{c}\mu \mathrm{g} / 100 \mathrm{ml} \\
\text { of } \mathrm{EPV}^{*}\end{array}$ & $\begin{array}{c}\text { pPD } \ddagger \\
\text { (OD 530) }\end{array}$ \\
\hline & & $\mathrm{kg}$ & $\mu g$ & $\mu g / \mathrm{kg}$ & & \\
\hline 10 & 11 & 12.9 & 118 & 9.1 & 15.0 & 0.09 \\
\hline 1 & 4 & 9.2 & 11.9 & 1.2 & 2.0 & 0.01 \\
\hline 0.5 & 4 & 11.6 & 7.5 & 0.6 & 1.0 & 0.005 \\
\hline 0.1 & 4 & 12.5 & 1.6 & 0.15 & 0.2 & 0.001 \\
\hline
\end{tabular}

* EPV, estimated plasma volume.

$\ddagger$ pPD, p-phenylenediamine oxidase activity after the injection.

Role of Ceruloplasmin in Iron Metabolism 


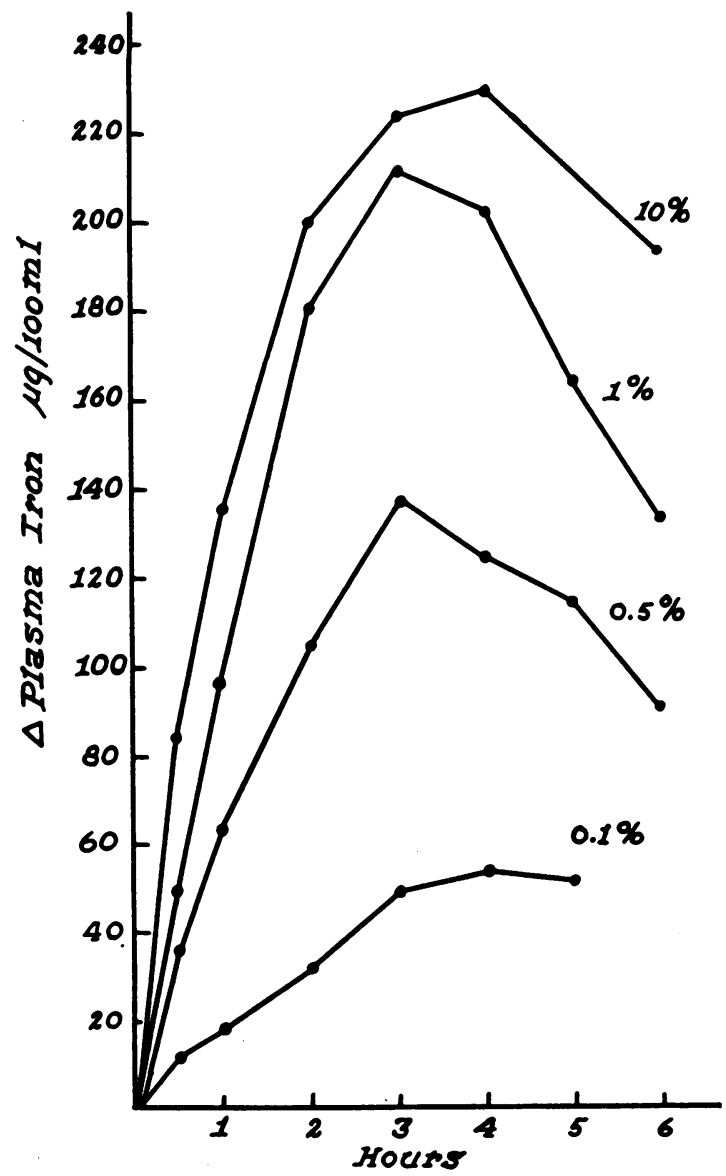

FIGURE 3 The change $(\Delta)$ in plasma iron after the injection of ceruloplasmin in four different doses, here designated in terms of intended per cent of normal (Table III). Each curve represents the mean of four studies.

results in no loss of either $\mathrm{pPD}$ or iron oxidizing activity (Table IV), but asialoceruloplasmin differs from native ceruloplasmin in that it leaves the plasma within minutes and is sequestered in the liver (14).

Porcine asialoceruloplasmin was injected intravenously to determine if an active ferroxidase which is promptly deposited in hepatic parenchymal cells would be capable of inducing an increase in plasma iron.

Asialoceruloplasmin had little or no effect on the plasma iron as compared with an equivalent amount of native ceruloplasmin (Fig. 5B). Thus, it appears that the iron oxidizing activity of ceruloplasmin is carried out in the plasma.

Ceruloplasmin levels and iron metabolism in Wilson's disease. Hypoceruloplasminemia is a characteristic finding in patients with Wilson's disease. In view of the function of ceruloplasmin delineated in the above studies, disturbances of iron metabolism might be expected to occur in Wilson's disease.

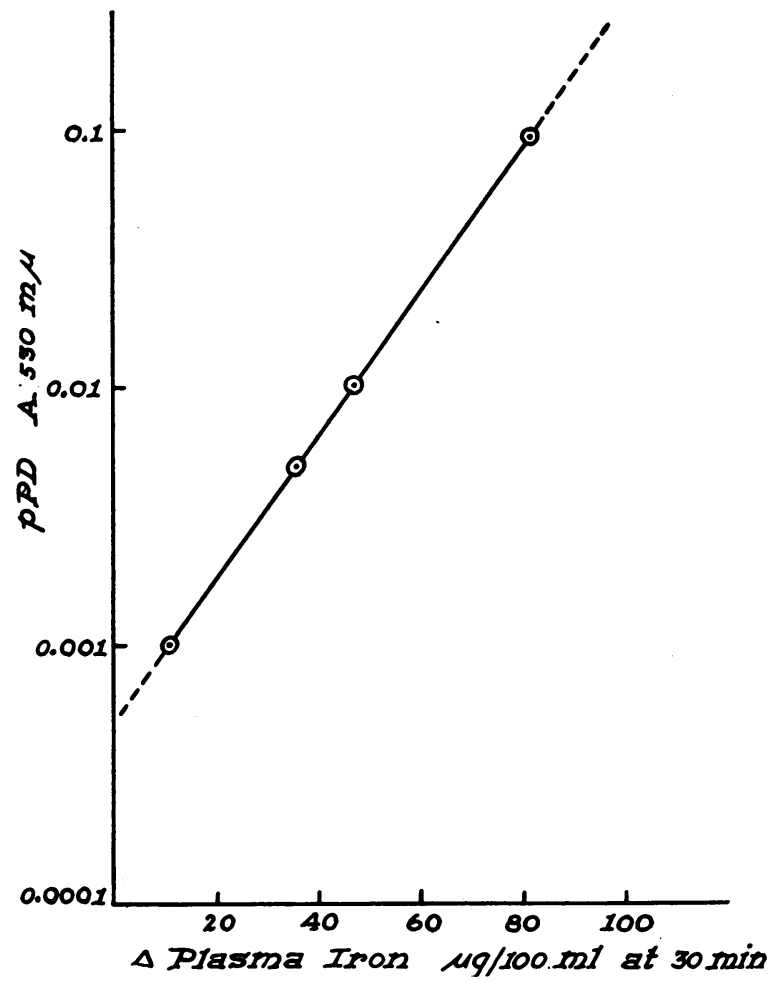

FIGURE 4 The relation of induced change in plasma ceruloplasmin (log scale) as measured by $p$-phenylenediamine oxidase (pPD) to the initial rate of plasma iron increase as estimated by the increase $30 \mathrm{~min}$ after injection.

Eight patients with Wilson's disease were studied to determine the degree of hypoceruloplasminemia and to search for abnormalities of iron metabolism (Table V). Of the eight patients, two (K.H. and C.H.) were studied before therapy. One patient (L.D.), reported in detail elsewhere (15), was 6 months pregnant; penicillamine had been discontinued for 7 months and reinstituted $1 \mathrm{wk}$ before the study. The remaining patients had taken 0.5-2 g penicillamine per day continuously for 5-12 yr.

The degree of ceruloplasmin deficiency in these eight patients was assessed by means of multiple procedures.

\section{TABLE IV}

Comparison of the Biochemical Properties of Porcine, Human, and Rat Ceruloplasmin and Porcine Asialoceruloplasmin

\begin{tabular}{|c|c|c|c|c|}
\hline $\begin{array}{l}\text { Relative } \\
\text { activity }\end{array}$ & $\begin{array}{l}\text { Porcine } \\
\text { cerulo- } \\
\text { plasmin }\end{array}$ & $\begin{array}{c}\text { Rat } \\
\text { cerulo- } \\
\text { plasmin }\end{array}$ & $\begin{array}{c}\text { Human } \\
\text { cerulo- } \\
\text { plasmin }\end{array}$ & $\begin{array}{c}\text { Porcine } \\
\text { asialocerulo } \\
\text { plasmin }\end{array}$ \\
\hline $\begin{array}{l}\mathrm{pPD} / \mathrm{Cu}, \\
O D 530 / \mu \mathrm{g}\end{array}$ & 0.34 & 0.2 & 0.29 & 0.43 \\
\hline $\begin{array}{l}\text { Ferroxidase/Cu } \\
\mu m o l e s / h r \text { per } \mu g\end{array}$ & 72 & 0.06 & 29 & 87 \\
\hline 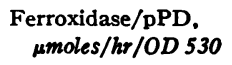 & 208 & 3 & 103 & 204 \\
\hline
\end{tabular}




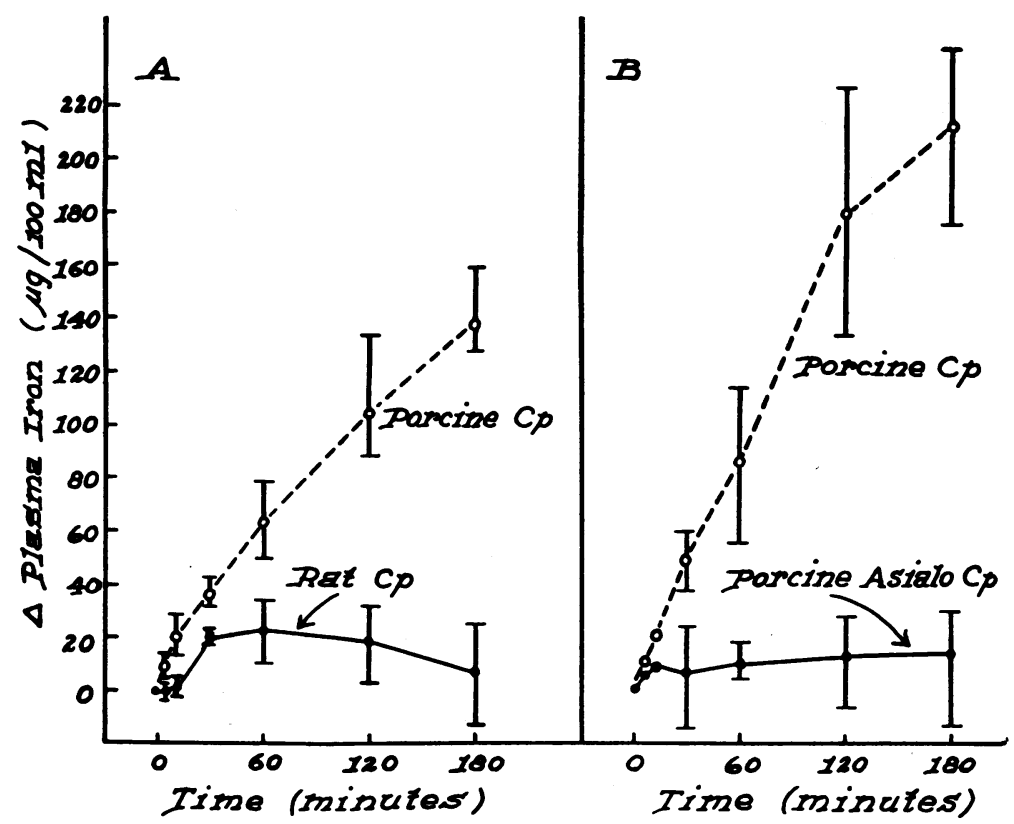

Figure 5 The effect of rat ceruloplasmin ( $\mathrm{Cp}$ ) and porcine asialoceruloplasmin (Asialo $\mathrm{Cp}$ ) on plasma iron in copper-deficient swine. $A$ : Rat ceruloplasmin and porcine ceruloplasmin are compared in a " $0.5 \%$ of normal" dose (Table III). B: Porcine asialoceruloplasmin and ceruloplasmin are compared in a " $1 \%$ of normal" dose (Table III). Bars indicate total range. Both rat ceruloplasmin and porcine asialoceruloplasmin are very much less effective than porcine ceruloplasmin.

Plasma pPD oxidase activity varied from 0.003 to 0.090 , or from 1 to $29 \%$ of the normal mean. Two of the eight patients (B.S. and D.H.) had $\mathrm{PPD}$ values at or near the levels that appeared to be associated with the onset of hypoferremia in pigs $(0.0006-0.007$ or $0.1-1 \%$ normal). In the remaining six patients, $\mathrm{pPD}$ values greater than 0.010 ( $3 \%$ of normal) were observed. All patients were found to have hypocupremia and reduced

TABLE V

Plasma Ferroxidase and Iron Metabolism in Wilson's Disease

\begin{tabular}{|c|c|c|c|c|c|c|c|c|}
\hline \multirow[b]{2}{*}{ Subject } & \multicolumn{2}{|c|}{ pPD oxidase } & \multirow[b]{2}{*}{$\begin{array}{c}\text { Total } \\
\text { ferroxidase }\end{array}$} & \multirow{2}{*}{$\begin{array}{l}\text { Cerulo- } \\
\text { plasmin } \\
\text { ferroxidase }\end{array}$} & \multirow{2}{*}{$\begin{array}{l}\text { Noncerulo- } \\
\text { plasmin } \\
\text { ferroxidase }\end{array}$} & \multirow[b]{2}{*}{ Citrate } & \multirow[b]{2}{*}{$\begin{array}{c}\text { Transferrin } \\
\text { saturation }\end{array}$} & \multirow[b]{2}{*}{$\begin{array}{l}\text { Marrow } \\
\text { iron* }\end{array}$} \\
\hline & OD 530 & $\begin{array}{c}\% \text { of } \\
\text { normal }\end{array}$ & & & & & & \\
\hline \multirow[t]{2}{*}{$\begin{array}{l}\text { Normal Mean } \\
\text { Rangeł }\end{array}$} & $\begin{array}{c}0.31 \\
0.22-0.41\end{array}$ & $\begin{array}{c}100 \\
71-132\end{array}$ & $\begin{array}{c}53 \\
40-67\end{array}$ & $\begin{array}{c}37 \\
21-52\end{array}$ & $\begin{array}{c}17 \\
7-27\end{array}$ & $\begin{array}{c}25 \\
11-39\end{array}$ & $20-45$ & \\
\hline & & \multicolumn{4}{|c|}{ umoles/ml per $\mathrm{hr}$} & $\mu g / m l$ & $\%$ & \\
\hline B. S. & 0.003 & 1 & 11 & 1 & 10 & 23 & 26 & $\downarrow$ \\
\hline D. H. & 0.004 & 1.3 & 9 & 2 & 7 & 19 & 13 & 0 \\
\hline R. W. & 0.010 & 3.2 & 11 & 2 & 9 & 23 & 21 & - \\
\hline K. H. & 0.011 & 3.5 & 16 & 1 & 15 & 37 & 17 & 0 \\
\hline C. H. & 0.013 & 4.2 & 16 & 2 & 14 & $36 \S$ & 9 & 0 \\
\hline C. S. & 0.035 & 11 & 17 & 3 & 14 & 228 & 38 & $\uparrow$ \\
\hline L. D.\| & 0.055 & 18 & 21 & 7 & 14 & 31 & 30 & $\uparrow$ \\
\hline N.W. & 0.090 & 29 & 25 & 5 & 20 & 41 & 9 & 0 \\
\hline
\end{tabular}

* 0 , absent; $\downarrow$, decreased; $\uparrow$, increased.

$\ddagger$ Mean \pm 2 sD.

$\S$ Citrate performed on a specimen different from that used in other studies.

|| Subject was pregnant at the time of study. 
values for total and ceruloplasmin ferroxidase. Values for plasma citrate, which is chiefly responsible for the nonceruloplasmin ferroxidase activity (3), were normal in seven patients and slightly increased in one.

Of the eight patients, four (D.H., K.H., C.H., and N.W.) were judged to be deficient in iron on the basis of absent bone marrow iron stores and reduced values for transferrin saturation. One of these (D.H.) had excessive menstrual blood loss, but in the other three, clinical evaluation did not reveal a cause for iron deficiency. In a fifth patient (B.S.) marrow iron stores were decreased but not absent, and in a sixth (R.W.), transferrin saturation was at the lower limit of normal. Both were young males with no history of blood loss. Only two of the eight patients (C.S. and L.D.) had no evidence of iron deficiency, and in both of these plasma ceruloplasmin concentration was greater than $10 \%$ of normal.

\section{DISCUSSION}

The data reported herein support the concept that ceruloplasmin is essential to the normal movement of iron from cells to plasma. Ceruloplasmin appears to act by virtue of its ferroxidase activity which facilitates transferrin formation, as presented schematically in Fig. 6. Evidence for these conclusions will be summarized below, and several physiologic and pathologic implications of the data will be discussed briefly.

Evidence that ceruloplasmin is necessary for optimal flow of iron from cells to plasma. It was demonstrated previously that mucosal cells, hepatic parenchymal cells, and reticuloendothelial cells of swine deficient in copper are capable of taking up iron, but fail to release it to the plasma at the normal rate (4). In the present study, these abnormalities in iron metabolism were shown to be associated with a severe deficiency of enzymatically active ceruloplasmin. As copper deficiency

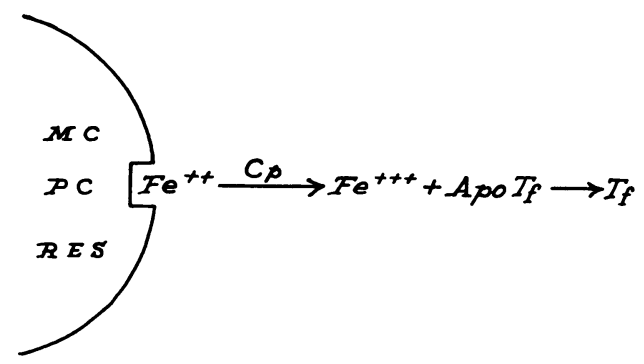

Figure 6 Proposed scheme for the role of ceruloplasmin in iron metabolism, according to the hypothesis of Osaki and coworkers (1). Iron, in the form of ferrous ion $\left(\mathrm{Fe}^{++}\right)$ is presented to the surface of mucosal cells (MC), parenchymal cells (PC), and cells of the reticuloendothelial system (RES). Ceruloplasmin ( $\mathrm{Cp}$ ) is required for optimal oxidation to ferric ion $\left(\mathrm{Fe}^{+++}\right)$, in which form iron combines with apotransferrin (Apo Tf) to form transferrin (Tf). developed, plasma ceruloplasmin levels decreased rapidly, reaching less than $1 \%$ of the normal mean at $10-12 \mathrm{wk}$ of age (Table I, Fig. 1). These animals therefore represent a model in which the physiologic consequences of ceruloplasmin lack should be apparent.

One of the signs of restricted reticuloendothelial iron outflow in copper-deficient pigs is the development of transient hypoferremia (4). In the present study, hypoferremia was observed only after a reduction of plasma ceruloplasmin to less than $1 \%$ of the normal level. The demonstrataion of such a sequence of events is a prerequisite to the acceptance of a cause and effect relationship between hypoceruloplasminemia and the hypoferremia. Later in the course of copper deficiency, the plasma iron increases as a consequence of a diminished flow of iron from transferrin to marrow, as discussed in an earlier publication (4).

The administration of ceruloplasmin to copper-deficient pigs was followed by a prompt and appreciable increase in plasma iron (Fig. 3). Earlier studies of nonsteady-state ferrokinetics following ceruloplasmin administration indicated that the increase is due to iron flowing into plasma, presumably from reticuloendothelial or hepatic parenchymal cells (5). Thus, ceruloplasmin administration has been shown to correct the defect in cellular iron outflow which is observed in copper deficiency.

The effect of ceruloplasmin cannot be explained by the copper contained therein (5). The administration of inorganic copper induced an increase in plasma iron, but it was necessary to give $100-150 \mu \mathrm{g} / \mathrm{kg}$ of inorganic copper in order to approximate the effect of $0.6-1.2 \mu \mathrm{g} / \mathrm{kg}$ of ceruloplasmin copper (Figs. 2, 3). Furthermore, the plasma iron response to this relatively high dose of inorganic copper was delayed as compared with the response to ceruloplasmin, and the delay was associated with an increase in plasma ceruloplasmin of an order that would in itself stimulate iron outflow (Fig. 2). Thus, it appears that copper exerts its effect on plasma iron only by making ceruloplasmin synthesis possible.

Evidence that the effect of ceruloplasmin on iron metabolism is due to its ferroxidase activity. The ability of the hypoceruloplasminemic pig to retain injected ferrous iron in the plasma was impaired (Table II). This abnormality was related to the oxidation state of the iron since retention of ferric iron was unimpaired. Failure to retain iron in plasma implies that the iron did not become bound to transferrin. Thus, ceruloplasmin appears to be essential to an optimal rate of transferrin formation from ferrous iron. The nonenzymatic rate of iron oxidation was not adequate to insure complete iron-binding in this system. These observations constitute an in vivo demonstration of the abnormality in iron binding in ceruloplasmin deficiency predicted 


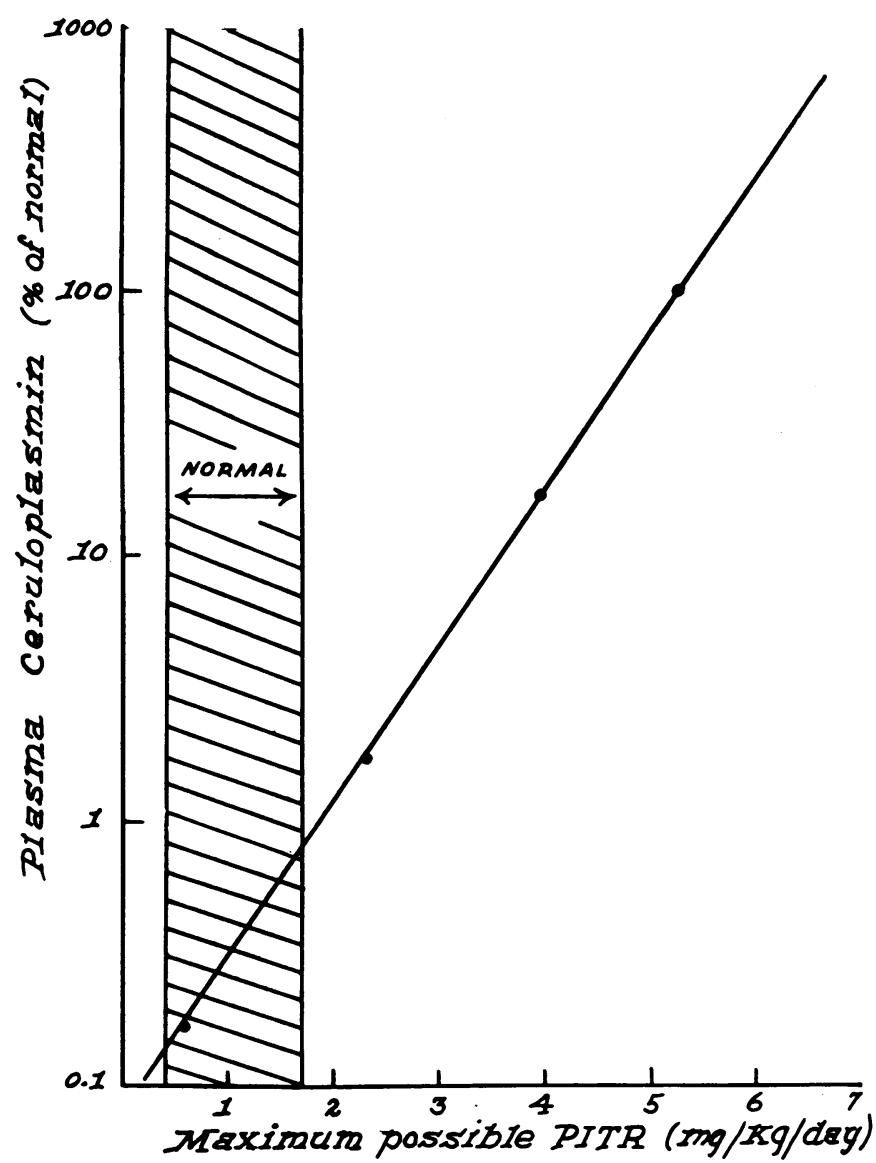

FIGURE 7 The relation of plasma ceruloplasmin levels to the theoretical maximum possible rate of plasma iron turnover. The shaded area indicates the normal range of plasma iron turnover. Only $1 \%$ of the normal level of ceruloplasmin is required for normal rates of iron turnover; however, much larger amounts are required under circumstances in which iron turnover increases.

by Osaki, Johnson, and Frieden on the basis of in vitro investigations (1).

Rat ceruloplasmin was very much less effective than porcine ceruloplasmin in inducing increases in plasma iron (Fig. 5A). Since rat ceruloplasmin differs from porcine in that the former possesses little ferroxidase activity, this observation implies that for a given ceruloplasmin to be active, it must possess adequate ferroxidase activity.

It has been proposed by others that ceruloplasmin functions by transferring its copper to a critical intracellular site $(16,17)$. Our data do not support this concept in regard to the iron-oxidizing function of ceruloplasmin since asialoceruloplasmin, a protein which possesses ferroxidase activity but which is deposited in hepatic parenchymal cells within minutes (14), was considerably less active than the native protein in inducing an increase in plasma iron (Fig. 5B). These studies suggest that ceruloplasmin functions intravascularly, probably at the cell membrane-plasma interface (Fig. 6), rather than intracellularly.

Physiologic and pathologic significance of the ceruloplasmin effect. The data presented indicate that only a small fraction, probably less than $1 \%$ of the ceruloplasmin in the circulation of normal pigs, is required to maintain a normal cell to transferrin flow of iron. Hypoferremia did not occur in the copper-deficient animals until the plasma ceruloplasmin activity decreased to less than $1 \%$ of the normal level. The plasma iron concentration did not increase after the injection of copper until the ceruloplasmin activity reached $1 \%$ of the normal level. An amount of ceruloplasmin, which increased the plasma ceruloplasmin activity to $0.1 \%$ of the normal level, induced a measurable increase in plasma iron (Fig. 3). Thus, in the normal animal, a considerable excess of ceruloplasmin is present. 
The logarithmic nature of the ceruloplasmin doseresponse curve (Fig. 4) has several interesting physiologic implications. These can be appreciated more readily by recalculating the data in Fig. 4 so as to present the relationship between plasma ceruloplasmin in "per cent of normal" and the maximal possible plasma iron transport rate (Fig. 7).

Standing in contrast to the small amounts of ceruloplasmin that appear to be adequate in the normal situation are the large amounts necessary to support the increased rates of iron turnover found in pathologic circumstances, such as hemolysis or hemorrhage. It appears that the normal ("100\%") level of ceruloplasmin will support a plasma iron transport rate of $5.2 \mathrm{mg} / \mathrm{kg}$ per day, or about five times the normal rate. Plasma iron transport rates of this magnitude have been observed in several experimentally induced anemias in swine (18). Thus, the amount of circulating ceruloplasmin, although greatly exceeding that necessary for the normal animal, may be required under pathologic circumstances.

On the other hand, it seems unlikely that the plasma ferroxidase activity becomes a rate-limiting step in iron metabolism in human disease. Instead, the ceruloplasmin concentration, as reflected by plasma copper levels, can and does increase above normal in many anemias associated with an increased plasma iron transport rate (19).

Since Wilson's disease is usually accompanied by ceruloplasmin deficiency, it might be anticipated that this disease would be associated with abnormalities in iron metabolism similar to those seen in the copper-deficient pig. Therefore, it was of interest to search for such abnormalities and to relate them to the degree of hypoceruloplasminemia.

In only two of eight patients with Wilson's disease was the ceruloplasmin activity near or below $1 \%$ of the normal mean, the level at which the first signs of abnormal iron metabolism were observed in copper-deficient swine. In the other six patients the values ranged from 3 to $29 \%$ of normal (Table V). In a previous report from this laboratory (20), plasma ceruloplasmin was measured by an immunologic method in 28 patients with Wilson's disease, and values from 2 to $22 \mathrm{mg} / 100 \mathrm{ml}$ (normal, 27-38) were obtained. In another study (21), plasma ceruloplasmin was found to exceed $5 \mathrm{mg} / 100 \mathrm{ml}$ (normal, 20-35) in 84 of 111 patients with the disease, but the degree of deficiency in the 27 patients with less than $5 \mathrm{mg} / 100 \mathrm{ml}$ was not presented. These observations indicate that most patients with Wilson's disease maintain a ceruloplasmin level that may be presumed to be adequate to provide for a normal plasma iron transport rate. This may account for the paucity of reports suggesting that iron metabolism is abnormal in Wilson's disease. In addition it should be pointed out that the plasma iron transport rate of growing pigs (22) is twice that of the nongrowing human subjects, and that for this reason a deficiency of ceruloplasmin would be more readily manifest in the pig than in man.

The only abnormality in iron metabolism found in our patients was iron deficiency, occurring in at least four and possibly six of the eight patients. Relatively high values for ceruloplasmin were found in the two patients with no iron deficiency. Iron deficiency is a manifestation of copper deficiency in swine given iron by mouth. This occurs because of defective iron absorption, a consequence of impaired mucosal cell-to-plasma iron transfer (4). Other investigators have reported the occurrence of unexplained iron deficiency in Wilson's disease (23). However, the number of patients in which careful studies of iron stores have been made is too small to establish that iron deficiency occurs with increased frequency in this disorder. In order to be certain, more patients must be studied, especially those with the severest degrees of hypoceruloplasminemia.

\section{ACKNOWLEDGMENTS}

We are indebted to Miss Jacqueline Thomas, Mrs. Alice Tustison, Mr. George Trappett, and Mr. Dale Chlarson for expert technical assistance.

Mr. Robert G. Eggert of the American Cyanamid Co. kindly provided supplies of the intramuscular iron preparation used (Pigdex), and Dr. Fenimore T. Johnson of the Upjohn Co. supplied heparin for use as an anticoagulant.

The studies were supported in part by a research grant (AM-04495), a graduate training grant (2A-5098), and a clinical research center grant (FR-0064) from the National Institutes of Health, Bethesda, Maryland. Dr. Roeser was supported by an Overseas Scholarship of the Royal Australasian College of Physicians.

\section{REFERENCES}

1. Osaki, S., D. A. Johnson, and E. Frieden. 1966. The possible significance of the ferrous oxidase activity of ceruloplasmin in normal human serum. J. Biol. Chem. $241: 2746$.

2. Osaki, S. 1966. Kinetic studies of ferrous ion oxidation with crystalline human ferroxidase (ceruloplasmin). J. Biol. Chem. 241: 5053.

3. Lee, G. R., S. Nacht, D. Christensen, S. P. Hansen, and G. E. Cartwright. 1969. The contribution of citrate to the ferroxidase activity of serum. Proc. Soc. Exp. Biol. Med. 131: 918.

4. Lee, G. R., S. Nacht, J. N. Lukens, and G. E. Cartwright. 1968. Iron metabolism in copper deficient swine. J. Clin. Invest. 47: 2058.

5. Ragan, H. A., S. Nacht, G. R. Lee, C. R. Bishop, and G. E. Cartwright. 1969. Effect of ceruloplasmin on plasma iron in copper-deficient swine. Amer. J. Physiol. 217: 1320 .

6. Lahey, M. E., C. J. Gubler, M. S. Chase, G. E. Cartwright, and M. M. Wintrobe. 1952. Studies in copper metabolism. II. Hematologic manifestations of copper deficiency in swine. Blood. $7: 1053$. 
7. Nacht, S., G. R. Lee, and G. E. Cartwright. 1968. Large scale preparation of porcine ceruloplasmin. Fed. Proc. 27: 482. (Abstr.)

8. Morell, A. G., C. J. A. van den Hamer, I. H. Scheinberg, and G. Ashwell. 1966. Physical and chemical studies on ceruloplasmin. IV. Preparation of radioactive, sialic acid-free ceruloplasmin labeled with tritium on terminal D-galactose residues. J. Biol. Chem. 241: 3745.

9. Bates, G. W., C. Billups, and P. Saltman. 1967. The kinetics and mechanism of iron (III) exchange between chelates and transferrin. I. The complexes of citrate and nitrilotriacetic acid. J. Biol. Chem. 242: 2810.

10. Ravin, H. A. 1961. An improved colorimetric enzymatic assay of ceruloplasmin. J. Lab. Clin. Med. 58: 161.

11. Trinder, P. 1956. The improved determination of iron in serum. J. Clin. Pathol. 9: 170.

12. Cartwright, G. E. 1968. Diagnostic Laboratory Hematology. Grune \& Stratton, Inc., New York. 4th edition.

13. Bush, J. A., W. N. Jensen, G. E. Cartwright, and M. M. Wintrobe. 1955. Blood volume studies in normal and anemic swine. Amer. J. Physiol. 181: 9.

14. Morell, A. G., R. A. Irvine, I. Sternleib, I. H. Scheinberg, and G. Ashwell. 1968. Physical and chemical studies on ceruloplasmin. V. Metabolic studies on sialic acid-free ceruloplasmin in vivo. J. Biol. Chem. 243: 155.

15. Deiss, A., G. R. Lee, and G. E. Cartwright. 1970. Hemolytic anemia in Wilson's disease. Ann. Intern. Med. $73: 413$.

16. Broman, L. 1966. The function of ceruloplasmin-a moot question. In Molecular Basis of Some Aspects of
Mental Activity. O. Walaas, editor. Academic Press, Inc., New York. 2: 1502.

17. Shokeir, M. H. K., and D. C. Shreffler. 1969. Cytochrome oxidase deficiency in Wilson's disease: a suggested ceruloplasmin function. Proc. Nat. Acad. Sci. 62 : 867.

18. Jensen, W. N., J. A. Bush, H. Ashenbrucker, G. E. Cartwright, and M. M. Wintrobe. 1956. The kinetics of iron metabolism in normal growing swine. J. Exp. Med. 103: 145.

19. Cartwright, G. E., C. M. Huguley, Jr., H. Ashenbrucker, J. Fay, and M. M. Wintrobe. 1948. Studies on free erythrocyte protoporphyrin, plasma iron and plasma copper in normal and anemic subjects. Blood. 3: 501 .

20. Cartwright, G. E., H. Markowitz, G. S. Shields, and M. M. Wintrobe. 1962. Studies on copper metabolism. XXIX. A critical analysis of serum copper and ceruloplasmin concentrations in normal subjects, patients with Wilson's disease and relatives of patients with Wilson's disease. Amer. J. Med. 28: 555.

21. Sternleib, I., and I. H. Scheinberg. 1965. The diagnosis of Wilson's disease in asymptomatic patients. J. Amer. Med. Ass. 183: 747

22. Bush, J. A., W. N. Jensen, J. W. Athens, H. Ashenbrucker, G. E. Cartwright, and M. M. Wintrobe. 1956. Studies on copper metabolism. XIX. The kinetics of iron metabolism and erythrocyte life-span in copper deficient swine. J. Exp. Med. 103: 701.

23. O'Reilly, S., M. Pollycove, and W. J. Banks. 1968 . Iron metabolism in Wilson's disease: a kinetic study with iron ${ }^{50}$. Neurology. 18: 634 . 